\title{
The Endplate and Trabecular Bone in Lumbar Degenerative Disc Disease: A Narrative Review
}

\author{
Tom Marjoram ${ }^{1}$
}

Accepted: 29 January 2020 / Published online: 6 February 2020

(C) The Author(s) 2020

\begin{abstract}
To review the current knowledge surrounding degenerative disc disease focusing on the changes taking place in the end plate and trabecular bone. A narrative review of the current literature. An age-related reduction in blood supply to the disc contributes to tissue degradation. Degeneration, separate from this process, represents a disruption of the normal homeostasis. A process of vascular and sensory nerve in-growth in the annulus and localised areas of the end plate is associated with markers of inflammation and may represent a pain source. Treatment with local anti-inflammatories has, at best, mixed results. Bone mechanical indentation testing has been used to classify changes in ageing and degeneration demonstrating a location-dependant reduction in strength specific to each process. Modic changes include a process of inflammation, alteration of the mechanical and chemical environment and changes in bone turnover. The underlying cause for their development has multiple explanations including mechanical overload and microfracture, infection and inflammation in response to herniation of disc material through the end plate. We do know, however, that they seem to be at least partially reversible and not all are symptomatic. This reversibility potentially indicates an avenue of exploration for therapy. Restoring the complex balance of disc homeostasis may hold some promise and will rely on greater understanding of the pathological and material changes occurring at the disc-bone interface and their correlation with clinical imaging. Current treatment may be optimised with an understanding of the mechanical environment of the disc in patient subgroups.
\end{abstract}

Keywords Back pain $\cdot$ Disc degeneration $\cdot$ Modic changes $\cdot$ Histology

\section{Introduction}

Low back pain is an established and significant health problem [1] with not only health but also with economic impacts. Wynne-Jones used pooled estimates to find $32 \%$ of the working age population suffering with low back pain will not have returned to work after 1 month [2]. In Europe the economic cost of back pain due to time lost from work is estimated to be $€ 12$ billion, affecting up to $47 \%$ of working age men [3]. Cheung et al. found that $40 \%$ of those under 30 displayed MRI evidence of lumbar disc degeneration which increased to $90 \%$ by 55 years of age [4]; they also found a strong correlation between disc degeneration and low back pain.

This article is part of the Topical Collection on Surgery

Tom Marjoram

tommarjoram@doctors.org.uk

1 Norfolk and Norwich University Hospital, Colney Lane, Norwich, England NR4 7UY
The adult intervertebral disc is avascular, relying on the adjacent vertebral endplate for nutritional support $[5,6]$. Macroscopically the disc consists of an outer annulus and a central nucleus. The annulus connects to the end plate which consists of cartilaginous and bony portions.

Degeneration of the intervertebral disc and its adjacent end plates is complex and multifactorial with genetic and environmental influences [7, 8]. We know from previous work that the disc undergoes an ageing process, and distinguishing this from degeneration can be difficult [9]. Dehydration of the disc can be a normal part of this ageing process [10]. Dehydration has been shown to significantly alter the stress transfer to the end plate causing fracture and remodelling altering the nutrient transfer further contributing to degeneration [11]. In the degenerative disc, it has been shown that the density of neurones increases and that areas of the disc that usually have no innervation can become newly populated with neurones $[12,13]$; this has been associated specifically with damaged areas of the disc by Lama et al. [14]. This neoinnervation implicates the disc as a contributing source of pain. 


\section{Mechanical Degeneration of the Endplate}

Degeneration of the disc is likely to represent a disruption of its normal homeostasis. This may be precipitated by excessive load which has been shown to inhibit the normal synthesis of extracellular proteins [15]. It has been well established that vertebral trabecular bone adjacent to the endplate undergoes a process of microfracture and healing in degeneration [16]. Investigating this mechanical overload hypothesis, mechanical testing has been undertaken on the micro- and nanoscales. Oliver and Pharr published their technique for calculating the elastic modulus of a material using the unloading section of the indentation curve, and this is now widely used [17]. Hou et al. performed indentation on cadaveric vertebral specimens. They found that the inferior lumbar endplate withstood a higher load to failure that the peripheral regions had a higher load to failure and a non-uniform decrease in load to failure in those with degenerate discs (the peripheral regions were less affected than the already weaker central regions further exaggerating the relative difference between the central and the peripheral regions). They also measured bone mineral density with DEXA and found that with a decrease in bone density came a uniform decrease in load to failure, implying that the osteopenia associated with ageing is mechanically separate from the process of degeneration [18].

Liu et al. analysed cadaveric samples with degeneration on MRI using $3 \mathrm{~mm}$ spherical tip indentation [19]. They concluded that stiffness and strength both decreased with signs of disc degeneration. On a smaller scale, nanoindentation has the advantage of applying significantly lower loads therefore measuring closer to true material properties (rather than a combination of material and structural). Dall'Ara [20] working on dry and embedded cadaveric vertebral tissue investigated the anisotropy of the bone as a material as well as the elastic properties (including of the osteophytes). They found osteophytes to have a lower elastic modulus (10.9 GPa) and there were demonstrable differences depending on the direction of the applied force (anisotropy) with axial being highest (14.6 GPa), something to be taken into consideration when comparing methodologies. We can conclude from the literature that mechanical changes clearly occur in the context of both ageing and degeneration, and characterization of these changes may hold clues about the underlying process of degeneration and also provide some clinical benefit in implant design and implantation.

\section{Degeneration and End plate Histology}

A sensible starting point is to investigate ageing separately from degeneration; Boos et al. established that ageing affects the blood supply to the end plate detrimentally. By investigating the changes found in cadaveric samples from age ranges foetal to 88 years, they conclude that their work 'provided clear histologic evidence for the detrimental effect of a diminished blood supply on the end plate, resulting in the tissue breakdown beginning in the nucleus pulposus and starting in the second life decade' [10].

Analysis of calcification of the endplate and its association with disc degeneration in the cervical spine showed that a decrease in pore number correlated with an increase in disc degeneration [21]. This was, however, pores $<300 \mu \mathrm{m}$ and most strongly for those between 10 and $50 \mu \mathrm{m}$. Suggesting this correlation is not as straight forward as it initially appears. An explanation could be that simple diffusion occurs most effectively across the small $(10-50 \mu \mathrm{m})$ thin-walled capillaries, and while the larger diameter channels may have a greater flow, their thicker walls will inhibit the process of diffusion that has been established as the main method of nutritional transport [22]. Contrary to this, Zehra et al. found porosity of the endplate to be more closely linked to mechanical loading than degeneration concluding 'disc degeneration is more closely linked to reduced disc stresses' [23]. It is of course not established that all pores contain vessels that contribute to diffusion. Malandrino found that porosity and diffusion of metabolites into the disc were not dependant on each other [24]; however, the movement of the water was related to the porosity (and therefore disc hydration). Histological and permeability analysis of the degenerate cartilaginous end plate has been undertaken by DeLucca et al. They found that with degeneration, the cartilaginous end plate permeability decreases. This not only would decrease the transport of nutrients into the disc but also would inhibit the transport of lactic acid out of the disc [25]. Some work suggests the contrary; however, Rodriguez et al. found, when looking at degenerate discs, that 'vertebral endplate porosity increased between 50 and $130 \%$ ' [26]. They also commented that perfusion increased with this suggesting the issue was not one of poor perfusion but more likely a cellular process.

When considering therapeutic intervention, especially disc preserving methods, an understanding of the perfusion to the disc (and how to assess this) will be vital in the successful implementation of such procedures.

\section{Neurone Involvement in Degeneration}

We know that in the normal spine, the outer $1 / 3$ of the annulus and the vertebral body contain nerve fibres [12]. A study of 69 normal spine samples using H\&E staining noted that 'Neurovascular bundles and intraosseous nerves were routinely identified within human vertebral bone' [27]. Is the presence of nerve fibres evidence that they are the source of pain? Freemont et al. used diseased human disc specimens using PGP 9.5 to stain for nerve fibres and substance $\mathrm{P}$ as a marker of nociception. They found that in their group of control samples, the nerve fibres seemed to be exclusively limited to the outer $1 / 3$ of the annulus as expected; however, in the diseased 
group, the nerve fibres were seen to extend into the middle and inner thirds in $46 \%$. Both groups of nerves expressed substance $\mathrm{P}$ suggesting that they could be involved in nociception [28].

A histological study of 15 patients with degenerative disc disease staining for substance $P$, calcitonin gene-related peptide (CGRP), neuropeptide Y (NPY) and PGP 9.5 (representing autonomic (PGP 9.5 and NPY) and sensory nerve fibres (PGP 9.5, substance P and CGRP)) showed that vascular channels around the end plate were accompanied by nerves of autonomic origin which they conclude and suggests that perfusion to the area and hence nutrition of the disc are under autonomic control. They found 'very localised' areas of increased nerve fibres staining for sensory neuropeptide CGRP (but not PGP 9.5) [29]. It is worth noting, however, that there was no overall difference in nerve density of the end plate, and the diseased groups had a mean age of 36 compared to 61 for the control samples - could these changes simply represent an ageing phenomenon? Work by Lama et al. would suggest that this very localised increase might represent the areas of local damage. Their work showed that nerve growth was limited only to areas of disrupted tissue [14].

Ohtori et al. performed histological analysis on spine samples with abnormal MRI (mainly focusing on Modic pathology). When staining for PGP 9.5, they found a significant difference between diseased and non-diseased groups. This correlated with a significant increase in TNF staining suggesting an inflammatory aetiology [30]. Niv et al. [31] commented on the success of vertebroplasty regardless of technique or cement volume indicating more than a pure mechanical improvement. They commented that the immediate effects are likely due to the toxicity of the cement to the nerve tissue which would support the hypothesis that the nerves within the vertebral body can be responsible for pain.

\section{Modic Changes and Degeneration}

The changes seen on MRI in degeneration include disc dehydration, loss of disc height and end plate signal changes (Modic changes) [32]. Later other parts of the functional spinal unit become affected including facet joint and ligamentum flavum. Both Modic and end plate changes are found in nonsymptomatic individuals.

Modic described 3 patterns of visible changes in the end plate on MRI [32]. It has been shown that Modic changes can transition from one type to another and that there is an increased incidence of radiological degenerative disc disease in those discs surrounded by Modic type changes in the adjacent vertebral bodies $[33,34]$. Hutton also documented that Modic changes do not necessarily transition in one direction, finding that some patients transitioned from type 2 back to type 1 suggesting the process might be at least partially reversible [35]. We know that type 2 Modic changes are the most prevalent in the symptomatic population, more common in degenerate disc disease and in the presence of spondylolisthesis $[36,37]$. The overall evidence about the clinical significance of Modic changes remains unclear [38]. One MRI study aver a 3 year period and found Modic changes did not correlate with the onset of low back pain [39].

There are several mechanisms proposed as the driver for Modic changes including mechanical changes as a consequence of disc degeneration resulting in abnormal load and shear stresses [40].

Another proposed mechanism is an autoimmune response to disc material originating from the nucleus pulposus that enters the vertebral body through microfractures in the end plate which are known to occur in degenerative disc disease [41]. Histological and CT analysis of bone from transpedicular biopsy in patients exhibiting Modic changes found that Modic type one was associated with changes that one would expect in high bone turnover situations. Modic type 2 changes showed reduced bone turnover/remodelling and Modic type 3 showed changes consistent with a sclerotic/stable phase [ $[42$, 43].

Ohtori [30] used immunohistology to stain for TNF and PGP 9.5 and found both to be increased in those with type 1 or 2 Modic changes suggesting inflammation and nerve ingrowth could be contributing factor to pain. Antonacci worked on bone sustaining osteoporotic fractures (not degeneration) finding that in areas of fracture, there is new bone formation as one would expect but also neovascularisation alongside an increase in localised nerve density when staining for PGP 9.5 [44]. We could draw from this (taking into account the work from Ohtori) that it is the inflammation associated with the fracture that stimulates this increase. The presence of inflammation is further supported by work from Rannou [45] who took serum high-sensitivity CRP measurements in those with different Modic type changes, finding levels were significantly higher in those with Modic type 1 . Dudli et al. [46] demonstrated in their rat model that the bone marrow (with some inflammatory upregulation from Il-1) mounts a response when exposed to nucleus pulposus cells potentially contributing to Modic changes. This is in keeping with work from the same group [47] in humans displaying Modic changes in which 'pro-inflammatory cross-talk between the bone marrow and adjacent discs' was found when comparing marrow and disc aspirated from levels displaying Modic changes or no changes in the same patients. Extrapolating this into clinical work, the results of a randomised controlled trial comparing and anti-TNF medication to placebo for back pain did not show any significant benefit [48] suggesting that the process is either not reversible or the true mechanism is not yet understood. It has been shown that intra-discal corticosteroids do improve pain again supporting the inflammation hypothesis [49]. 


\section{Modic Changes and Infection}

Stirling et al. proposed that these Modic changes could represent a form of chronic vertebral osteomyelitis associated with Propionibacterium acnes [50]. His paper found that 53\% of included patients with herniated lumbar discs were found to have anaerobic organisms isolated.

Albert took nuclear disc material from 61 patients undergoing lumbar discectomy. Patients were grouped according to their microbiological cultures (aerobic, anaerobic or no growth). Forty six percent of these patients had microbiological growth. In those with anaerobic growth, $80 \%$ developed new Modic changes, $0 \%$ of those with aerobic growth and $44 \%$ of those with no growth [51]. Propionibacterium acnes was the most cultured organism. It is worth noting that this study had very strict inclusion criteria.

\section{Modic Changes and Mechanics}

Analysis of extruded disc material at the time of discectomy in 51 patients found the presence of and percentage of end plate involvement of Modic changes both correlated with the presence of cartilaginous end plate in the extruded material [52]. This would infer that the pathology responsible for Modic changes weakens the anchorage of the cartilaginous end plate increasing the likelihood of it detaching. Investigating the mechanical and structural properties further, Liu et al [19] used cadaveric samples and micro-indentation to conclude that stiffness and strength of the end plate reduce with degenerative changes; when Modic changes were present, this was more pronounced.

A review [53] exploring Modic changes comments on the similarities with bone marrow lesions in knee osteoarthritis citing similar risk factors, pain profiles and evolution. The work concludes that structural damage allows the creation of a pro-inflammatory environment which causes nociception and an inflammatory signalling cascade in the bone marrow affecting both marrow composition osteoclast function. It highlights disc/endplate damage, composition of the bone marrow, occult infection, treatment effectiveness and further exploration of the link in osteoarthritis as areas in which further research is required.

The pathological process of Modic changes has yet to be fully understood; histological analysis has, however, shown a correlation with markers of inflammation and nerve ingrowth associated with type 1 changes. Histology has also shown features indicating that there is an alteration in the mechanical environment in which Modic changes exist - it is not clear if this is a cause or effect style relationship. Inflammation is involved, stimulating nerve and local vascular ingrowth. Further work is required for a full understanding and may prove useful when formulating a clinical solution to this significant health problem.

\section{Conclusion}

Degeneration represents a disruption of the homeostasis of the normal function of a healthy disc in susceptible individuals. It has been shown to be separate from the ageing process. Restoring this complex balance may hold some promise but identifying the correct patients in who a favourable environment can be achieved will rely on greater understanding of the pathological changes and their correlation with imaging modalities. The endplate is closely entwined with the homeostasis and mechanical environment of the disc, an unbalancing of one clearly affect the other. Matching pathology with symptoms is not straightforward. Markers of inflammation have been shown to be increased but treatment with antiinflammatories has produced mixed results. Non-uniform micromechanical strength reductions indicate that the homeostasis of the vertebral bone is affected which may hold some clues to the underlying pathology. Modic changes have multiple proposed underlying mechanisms including inflammation, infection, alteration of the mechanical and chemical environment and changes in bone turnover. We do know they seem to be partially reversible, perhaps an avenue of promise for therapy?

Acknowledgements Prof. I McNamara of the University of East Anglia \& Prof's S Best and R Cameron of the University of Cambridge Material Science department for expert guidance and supervision.

Funding Information Funding from The Gwen Fish Trust, Action Arthritis and The British Association of Spinal Surgeons contributing to the costs of Doctoral Research in this area of work.

Open Access This article is licensed under a Creative Commons Attribution 4.0 International License, which permits use, sharing, adaptation, distribution and reproduction in any medium or format, as long as you give appropriate credit to the original author(s) and the source, provide a link to the Creative Commons licence, and indicate if changes were made. The images or other third party material in this article are included in the article's Creative Commons licence, unless indicated otherwise in a credit line to the material. If material is not included in the article's Creative Commons licence and your intended use is not permitted by statutory regulation or exceeds the permitted use, you will need to obtain permission directly from the copyright holder. To view a copy of this licence, visit http://creativecommons.org/licenses/by/4.0/.

\section{References}

1. Dionne CE, Dunn KM, Croft PR. Does back pain prevalence really decrease with increasing age? A systematic review. Age Ageing. 2006;35(3):229-34.

2. Wynne-Jones G, Cowen J, Jordan JL, Uthman O, Main CJ, Glozier $\mathrm{N}$, et al. Absence from work and return to work in people with back pain: a systematic review and meta-analysis. Occup Environ Med. 2014;71(6):448-56.

3. Bevan PS. The Impact of Back Pain on Sickness Absence in Europe. The Work Foundation 2012;8. Available from; http:// 
www.theworkfoundation.com/DownloadPublication/Report/313 The $\% 20$ Impact $\% 20$ of $\% 20$ Back $\% 20$ Pain $\% 20$ on $\% 20$ Sickness $\%$ 20Absence\%20in\%20Europe\%20FINAL.pdf.

4. Cheung KMC, Karppinen J, Chan D, Ho DWH, Song Y-Q, Sham P, et al. Prevalence and pattern of lumbar magnetic resonance imaging changes in a population study of one thousand forty-three individuals. Spine. 2009;34(9):934-40.

5. Le CL, Binch AL, Thorpe AA, Hughes SP. Degeneration of the intervertebral disc with new approaches for treating low back pain. J Neurosurg Sci. 2015;59(1):47.

6. Lotz JC, Fields AJ, Liebenberg EC. The role of the vertebral end plate in low back pain. Global Spine J. 2013;3(3):153-63.

7. Stone MA, Williams F, Wolber L, Karppinen J, Maatta J. Twins UK heritability study of candidate low back pain phenotype shows vertebral endplate abnormalities to be heritable. Rheumatology (United Kingdom). 2013;52:i64-5.

8. Battié MC, Videman T, Levälahti E, Gill K, Kaprio J. Genetic and environmental effects on disc degeneration by phenotype and spinal level: a multivariate twin study. Spine. 2008;33(25):2801-8.

9. Adams MA, Roughley PJ. What is intervertebral disc degeneration, and what causes it? Spine. 2006;31(18):2151-61.

10. Boos N, Weissbach S, Rohrbach H, Weiler C, Spratt KF, Nerlich AG. Classification of age-related changes in lumbar intervertebral discs: 2002 Volvo award in basic science. Spine. 2002;27(23): 2631-44.

11. Massey CJ, van Donkelaar CC, Vresilovic E, Zavaliangos A, Marcolongo M. Effects of aging and degeneration on the human intervertebral disc during the diurnal cycle: a finite element study. $\mathrm{J}$ Orthop Res. 2012;30(1):122-8.

12. García-Cosamalón J, del Valle ME, Calavia MG, García-Suárez O, López-Muñiz A, Otero J, et al. Intervertebral disc, sensory nerves and neurotrophins: who is who in discogenic pain? J Anat. 2010;217(1):1-15.

13. Peng B, Wu W, Hou S, Li P, Zhang C, Yang Y. The pathogenesis of discogenic low back pain. J Bone Joint Surg (Br). 2005;87(1):62-7.

14. Lama P, Le Maitre CL, Harding IJ, Dolan P, Adams MA. Nerves and blood vessels in degenerated intervertebral discs are confined to physically disrupted tissue. J Anat. 2018;233(1):86-97.

15. Ishihara H, McNally DS, Urban JP, Hall AC. Effects of hydrostatic pressure on matrix synthesis in different regions of the intervertebral disk. J Appl Physiol. 1996;80(3):839-46.

16. Vernon-Roberts B, Pirie CJ. Healing trabecular microfractures in the bodies of lumbar vertebrae. Ann Rheum Dis. 1973;32(5):40612.

17. Oliver WC, Pharr GM. An improved technique for determining hardness and elastic modulus using load and displacement sensing indentation experiments. J Mater Res. 1992;7(6):1564-83.

18. Hou Y, Yuan W. Influences of disc degeneration and bone mineral density on the structural properties of lumbar end plates. Spine J. 2012;12(3):249-56.

19. Liu J, Hao L, Suyou L, Shan Z, Maiwulanjiang M, Li S, et al. Biomechanical properties of lumbar endplates and their correlation with MRI findings of lumbar degeneration. J Biomech. 2016;49(4): 586-93.

20. Dall'Ara E, Karl C, Mazza G, Franzoso G, Vena P, Pretterklieber M, et al. Tissue properties of the human vertebral body sub-structures evaluated by means of microindentation. J Mech Behav Biomed Mater. 2013;25:23-32.

21. Tomaszewski KA, Adamek D, Konopka T, Tomaszewska R, Walocha JA. Endplate calcification and cervical intervertebral disc degeneration: the role of endplate marrow contact channel occlusion. Folia Morphol (Warsz). 2015;74(1):84-92.

22. Holm S, Maroudas A, Urban JP, Selstam G, Nachemson A. Nutrition of the intervertebral disc: solute transport and metabolism. Connect Tissue Res. 1981;8(2):101-19.
23. Zehra U, Robson-Brown K, Adams MA, Dolan P. Porosity and thickness of the vertebral endplate depend on local mechanical loading. Spine. 2015;40(15):1173-80.

24. Malandrino A, Lacroix D, Hellmich C, Ito K, Ferguson SJ, Noailly $\mathrm{J}$. The role of endplate poromechanical properties on the nutrient availability in the intervertebral disc. Osteoarthr Cartil. 2014;22(7): 1053-60.

25. DeLucca JF, Cortes DH, Jacobs NT, Vresilovic EJ, Duncan RL, Elliott DM. Human cartilage endplate permeability varies with degeneration and intervertebral disc site. J Biomech. 2016;49(4):550 7.

26. Rodriguez AG, Rodriguez-Soto AE, Burghardt AJ, Berven S, Majumdar S, Lotz JC. Morphology of the human vertebral endplate. J Orthop Res. 2012;30(2):280-7.

27. Antonacci MD, Mody DR, Heggeness MH. Innervation of the human vertebral body: a histologic study. J Spinal Disord. 1998;11(6): $526-31$

28. Freemont A, Peacock T, Goupille P, Hoyland J, O’Brien J, Jayson $M$. Nerve ingrowth into diseased intervertebral disc in chronic back pain. Lancet. 1997;350(9072):178-81.

29. Brown MF, Hukkanen MVJ, Mccarthy ID, Redfern DRM, Batten JJ, Crock HV, et al. Sensory and sympathetic innervation of the vertebral endplate in patients with degenerative disc disease. J Bone Joint Surg. 1997;79(1):7.

30. Ohtori S, Inoue G, Ito T, Koshi T, Ozawa T, Doya H, et al. Tumor necrosis factor-immunoreactive cells and PGP 9.5-immunoreactive nerve fibers in vertebral endplates of patients with discogenic low back pain and Modic type 1 or type 2 changes on MRI. Spine. 2006;31(9):1026-31.

31. Niv D, Gofeld M, Devor M. Causes of pain in degenerative bone and joint disease: a lesson from vertebroplasty. Pain. 2003;105(3): 387-92.

32. Modic MT, Masaryk TJ, Ross JS, Carter JR. Imaging of degenerative disk disease. Radiology. 1988;168(1):177-86.

33. Kerttula L, Luoma K, Vehmas T, Grönblad M, Kääpä E. Modic type I change may predict rapid progressive, deforming disc degeneration: a prospective 1-year follow-up study. Eur Spine J 2012;21(6):1135-42.

34. Kuisma M, Karppinen J, Haapea M, Niinimäki J, Ojala R, Heliövaara M, et al. Are the determinants of vertebral endplate changes and severe disc degeneration in the lumbar spine the same? A magnetic resonance imaging study in middle-aged male workers. BMC Musculoskelet Disord. 2008;9:51.

35. Hutton MJ, Bayer JH, Powell JM. Modic vertebral body changes: the natural history as assessed by consecutive magnetic resonance imaging. Spine. 2011;36(26):2304-7.

36. Arana E, Kovacs M, Royuela A, Estremera A, Asenjo B, Sarasíbar $\mathrm{H}$, et al. Modic changes and associated features in southern European chronic low back pain patients. Spine J. 2011;11(5): 402-11.

37. Kjaer P, Leboeuf-Yde C, Korsholm L, Sorensen JS, Bendix T. Magnetic resonance imaging and low back pain in adults: a diagnostic imaging study of 40-year-old men and women. Spine. 2005;30(10):1173.

38. Jensen RK, Leboeuf-Yde C. Is the presence of modic changes associated with the outcomes of different treatments? A systematic critical review. BMC Musculoskelet Disord. 2011;12:183.

39. Jarvik JG, Hollingworth W, Heagerty PJ, Haynor DR, Boyko EJ, Deyo RA. Three-year incidence of low Back pain in an initially asymptomatic cohort: clinical and imaging risk factors. Spine. 2005;30(13):1541-8.

40. Mok FPS, Samartzis D, Karppinen J, Fong DYT, Luk KDK, Cheung KMC. Modic changes of the lumbar spine: prevalence, risk factors, and association with disc degeneration and low back pain in a large-scale population-based cohort. Spine J. 2016;16(1):32-41. 
41. Ma X-L, Ma J-X, Wang T, Tian P, Han C. Possible role of autoimmune reaction in Modic type I changes. Med Hypotheses. 2011;76(5):692-4.

42. Perilli E, Parkinson IH, Truong L-H, Chong KC, Fazzalari NL, Osti OL. Modic (endplate) changes in the lumbar spine: bone microarchitecture and remodelling. Eur Spine J. 2015;24(9):1926-34.

43. Osti OL, Zahari S, Ooi J, Truong L, Perilli E, Fazzalari NL. Microstructure and Remodeling in Modic Changes. Spine Journal Meeting Abstracts 2010;13.

44. Antonacci MD, Mody DR, Rutz K, Weilbaecher D, Heggeness $\mathrm{MH}$. A histologic study of fractured human vertebral bodies. J Spinal Disord Tech. 2002;15(2):118-26.

45. Rannou F, Ouanes W, Boutron I, Lovisi B, Fayad F, Macé Y, et al. High-sensitivity C-reactive protein in chronic low back pain with vertebral end-plate Modic signal changes. Arthritis Care Res. 2007;57(7):1311-5.

46. Dudli S, Liebenberg E, Magnitsky S, Lu B, Lauricella M, Lotz JC. Modic type 1 change is an autoimmune response that requires a proinflammatory milieu provided by the 'Modic disc'. Spine J. 2018;18(5):831-44.

47. Dudli S, Sing DC, Hu SS, Berven SH, Burch S, Deviren V, et al. ISSLS PRIZE IN BASIC SCIENCE 2017: intervertebral disc/bone marrow cross-talk with Modic changes. Eur Spine J. 2017;26(5): $1362-73$.
48. Korhonen T, Karppinen J, Paimela L, Malmivaara A, Lindgren KA, Bowman C, et al. The treatment of disc herniation-induced sciatica with infliximab: one-year follow-up results of FIRST II, a randomized controlled trial. Spine. 2006;31(24):2759-66.

49. Zhang Y-H, Zhao C-Q, Jiang L-S, Chen X-D, Dai L-Y. Modic changes: a systematic review of the literature. Eur Spine J. 2008;17(10):1289-99.

50. Stirling A, Worthington T, Rafiq M, Lambert PA, Elliott TS. Association between sciatica and Propionibacterium acnes. Lancet. 2001;357(9273):2024-5.

51. Albert HB, Lambert P, Rollason J, Sorensen JS, Worthington T, Pedersen MB, et al. Does nuclear tissue infected with bacteria following disc herniations lead to Modic changes in the adjacent vertebrae? Eur Spine J. 2013;22(4):690-6.

52. Schmid G, Witteler A, Willburger R, Kuhnen C, Jergas M, Koester O. Lumbar disk herniation: Correlatlon of histologic findings with marrow signal intensity changes in vertebral endplates at MR imaging. Radiology. 2004;231(2):352-8.

53. Dudli S, Fields AJ, Samartzis D, Karppinen J, Lotz JC. Pathobiology of Modic changes. Eur Spine J. 2016;25(11):372334.

Publisher's Note Springer Nature remains neutral with regard to jurisdictional claims in published maps and institutional affiliations. 